\title{
EFFECT OF MARITAL COUNSELLING ON WOMEN'S ATTITUDE TOWARDS MARITAL STABILITY
}

\author{
DIMKPA, I. Daisy PhD \\ Department of Educational Foundations \\ Niger Delta University \\ Wilberforce Island, Bayelsa State. \\ email- daisdimkpadr@yahoo.com
}

\begin{abstract}
This study investigated the effect of marital counselling on women's attitude towards marital stability. The study adopted a pre-test post-test quasi experimental design. The sample consisted of 52 married women (academic and non-academic) staff of the Faculty of Education, University of Port-Harcourt, Rivers State of Nigeria. 26 each were assigned to experimental and control groups respectively. The participants were given a pre-test self-designed questionnaire titled 'Women's Attitude towards Marital Stability Questionnaire' (WATMSQ). The experimental group was lectured for a period of four weeks on marital counselling programme. After four weeks, the post test programme was administered on both groups. The results were analyzed using mean scores and standard deviation for the research questions and t-test for the research hypothesis. Result of the hypothesis indicated that there was a significant difference between the experimental group's mean scores which was higher than that of the control group. It showed that marital counselling had a significant effect on women's attitude towards marital stability. Based on the findings, the implications for counselling include organizing seminars and workshops by counsellors to teach women skills that will enhance positive marital attitudes, adoption of marital counselling programmes by employers of labour to assist women maintain desirable marital attitudes in order to promote their input at work, amongst others.
\end{abstract}

Key Words: Marital counselling, Marital stability, Women, Nigeria

\section{Introduction}

Marital stability is the relationship in which couples live together in marriage, enjoying the closest possible loving and fulfilling relationship without any intention of breakup (Adesanya, 2002). A peaceful relationship is achieved when married couples understand their 
individual roles and work together towards it. Adesanya (2002) identified certain factors that ensure marital stability such as economic wellbeing, responsiveness, among others. However, the strongest factor of marital stability is considered to be economic satisfaction (Adesanya, 2002). According to Owuamanam (1997), inadequate provision of essential needs for wives and children within the family is capable of creating tension, conflict and poor marital adjustment. Similarly, Owuamanan and Osakinle (2005) observed that marital instability in homes could lead to separation and divorce. In their own study, Ambakederemo and Ganagana (2006) found that marital instability is caused by sex-related issues, love and trust, socio-cultural factors, anti-social vices and lastly economic factors.

Although couples must work together to create stability in their marriage, the role played by women in this regard cannot be overemphasized. Women all over the world are known for their caring nature and ability to broker peace in order to maintain a stable home. It is even so in the African culture in general and Nigeria in particular where they are brought up to revere their husbands and endure all forms of injustices in order to gain the respect of society as responsible women. To this end, many women are seen in crusade grounds and some go to the extent of using charms so as to have a stable home. For example, AmaoKehinde (2002) in his study found that out of 547 cases of marital conflict investigated, 206 of them were resolved and 314 disintegrated their marriages due to conflicts and infertility. Some methods employed by couples in resolving marital conflicts include the traditional round-table settlement by both family members of married couples and intervention by close friends. In most cases, these methods are faulty, one-sided and could make matters worse.

The problem of this study therefore is that women have been observed to experience marital instability resulting from a number of factors notably economic, personality, psychological and socio-cultural (Dimkpa, 2007). Attitude developed by married women could be negative or positive depending on their individual circumstances. Most homes nowadays experience instability one way or the other. Marital instability is a serious problem which interferes with women's output to work, emotionally, educationally and socially. It could retard progress at work if women are not helped to imbibe the right attitude to marital stability. Conversely, stability in marriage is very important in bringing about commitment on women in particular in caring for their children's upbringing and discipline. Therefore for women to be happy in their 
marriage, it is necessary to correct some of their irrational behaviours towards marital stability. In this wise, marital stability counselling technique was utilized as a way of eliminating wrong/negative attitude towards marital stability.

Marital counselling involves series of marriage counselling sessions aimed at helping individuals to learn skills useful for resolving marital conflicts. Evidence has shown that it is beneficial for better understanding of marital roles (Ambakederemo \& Ganagana, 2006). Akande, Olowonirejuaro and Akuchie (2008) contended that attitudes are deeply rooted and influence success in many subjects. It is also an enduring trait in life which is a composite of many experiences, that could be positive or negative depending on the circumstances and experiences of individuals. According to Campbell (1993), attitude is a latent variable which could influence negative or positive action in an individual. For instance, a person's attitude could be as a result of the influence or impact made through a particular situation. Some people are predisposed to acting in a negative way based on certain conditions in marriage such as infidelity on the part of a spouse, environmental conditions, just to mention a few. Thus, the extent to which a person is able to communicate her concerns brings about changes in her attitude. Since marital conflicts might result from attitudinal problems of a spouse, this study investigated the effects of marital counselling on women's attitude towards marital stability in Rivers State of Nigeria.

\section{Purpose of the Study}

The purpose of this study was to examine the main and interactive effects of marital counselling on women's attitude towards marital stability by exposing them to a marital counselling programme aimed at helping them maintain marital stability.

\section{Research Questions}

The study examined the following questions:

1. What is the difference between the pre- and post test mean scores of the control and experimental groups before and after the treatment of the experimental group?

2. What is the difference between the post test mean scores of the control group and experimental group that received treatment after the experiment? 


\section{Research Hypothesis}

The following hypothesis was investigated:

1. The mean scores of the experimental group that received marital counselling programme and the control group will not differ significantly after four weeks of treatment.

\section{Method}

\section{Design:}

The study adopted a quasi experimental design of the pre-test and posttest control group. This involves a random assignment of subjects to experimental and control groups in which both underwent pre-test and post-test. The main focus of the study was to establish cause and effect relationship between two independent variables.

\section{Population:}

The population of the study comprised 67 women, academic and nonacademic staff of Faculty of Education, University of Port-Harcourt in Rivers State, Nigeria.

\section{Sample:}

For this study, only women who exhibited negative attitude towards marital stability were administrated the questionnaire. A total of 57 women married for more than five years responded to the main instrument known as Women's Attitude Towards Marital Stability Questionnaire (WATMSQ). However, only 52 questionnaires were properly completed and these 52 women were selected for the experiment. Simple random sampling was used in assigning participants into the experimental and control groups (26 in each group).

\section{Instrumentation}

The instrument employed in gathering data from the respondents was a 30-item self-designed questionnaire titled Women's Attitude towards Marital Stability Questionnaire (WATMSQ). The instrument consists of five major areas such as socio-economic, cultural, sex-related, communication and psychological aspects of attitude towards marital stability. The response format was a 4-point Scale of Strongly Agree $=4$, Agree $=3$, Disagree $=2$ and Strongly Disagree $=1$. The content validity of the instrument was established by a panel of four experts in Psychology, Guidance and Counselling from the University of Port-Harcourt who confirmed the instrument as measuring what it ought to measure. The reliability of the instrument was done using test re-test method. The 
instrument was administered twice within a period of two weeks by the researcher on a sample of 20 women who were not part of the participants of this study. It yielded a Pearson Product Moment Correlation Coefficient value of 0.76 .

\section{Method of Data Analysis:}

Means, standard deviation and t-test for the main hypothesis was used in analyzing the data. A higher score indicates more stable marital attitudes.

\section{Treatment Procedure:}

The WATMSQ was first administered on the 26 women as pre-test by the researcher. The scores obtained were recorded and subjected to means and standard deviation analysis.

The researcher met with the experimental group on a regular scheduled period for four weeks and exposed them to the WATMSQ programme, which sought to acquaint them with the need to imbibe positive marital attitudes. They were taught how to be responsible wives as well as maintaining a stable marriage. After the lectures, copies of the WATMSQ treatment programme were administered on the subjects to read and understand at home. A date was fixed for the experimental group to re-take the WATMSQ and the control group was only asked to complete the WATMSQ again, but not in the original form. Some of the items of the instrument were rearranged, which served as a control for test effects. The results were analyzed using t-test.

\section{Results}

Results of the study are presented in Tables 1 and 2:

Table 1: Differences between the mean scores of Pre- and Post tests of the Experimental and Control Group before and after treatment of the experimental Group

\begin{tabular}{|c|c|c|c|c|c|}
\hline \multirow{2}{*}{ Variables } & & \multicolumn{2}{c|}{$\begin{array}{c}\text { Pre-test score } \\
\text { before treatment }\end{array}$} & \multicolumn{2}{c|}{$\begin{array}{c}\text { Post test score } \\
\text { after treatment }\end{array}$} \\
\hline & $\mathbf{N}$ & $\mathbf{X}$ & SD & X & SD \\
\hline Experimental & 26 & 44.5 & 1.56 & 56.4 & 2.13 \\
\hline Control & 26 & 41.5 & 1.43 & 43.2 & 2.01 \\
\hline
\end{tabular}

Table 1 shows that the Pre-test mean score of the experimental group before treatment (44.5) is less than its Post-test mean score of (56.4) 
after treatment. Similarly, the Pre-test mean score of the control group without treatment (41.5) is less than the Post test mean score of (43.2).

Table 2: T-test Analysis on the Post-test Mean Scores of the Experimental and Control Group after 4 weeks

\begin{tabular}{|l|c|c|c|c|c|c|c|}
\hline \multicolumn{1}{|c|}{ Group } & N & $\mathbf{X}$ & SD & Df & t-cal & Table-t & Decision \\
\cline { 1 - 6 } Experimental & 26 & 56.4 & 2.13 & \multirow{2}{*}{24} & \multirow{2}{*}{$5 . .23^{*}$} & 1.96 & Rejected \\
\hline Control & 26 & 43.2 & 2.01 & & & & \\
\hline
\end{tabular}

Table 2 shows that the calculated $t$-value of 5.23 is higher than the table $\mathrm{t}$-value of 1.96 at 24 degree of freedom and the 0.05 level of significance. Therefore, the null hypothesis is rejected, indicating that there is a significant difference between the post-test mean scores of married women who received the treatment programme and the control group in favour of the experimental/treatment group with a higher mean score.

\section{Discussion}

The result of this study has shown that the pre-test mean score of the experimental group before treatment was (44.5), which was less than the post-test mean score of (56.4). Similarly, the pre-test mean score of the control group was (41.5), which was less than the post- test mean score of (43.2). This means that both groups had a higher mean at the post-test stage although the experimental group was observed to have s higher mean than the control group as seen in Table 1, which could be attributed to the treatment they received.

The main hypothesis to find out if significant differences occurred in the post-test of the treatment /experimental group after a period of four weeks as compared with the control group showed that they were different. The calculated $\mathrm{t}$-value of 5.23 was higher than the table value of 1.96 at the 0.05 level of significance. Specifically, the result in Table 2 shows that the experimental group had a higher mean score of (56.4) than the control group with a mean score of (43.2). This means that treatment with WATMSQ had a positive effect on the experimental group. This is not surprising as it has been consistently reported that counselling has a positive influence on people's attitudes and behaviours. This means that counselling is effective in changing many aspects of people's views on issues and that women have a positive attitude towards marital stability having undergone a marital counselling programme. Furthermore, it 
shows that the women were receptive to the information communicated to them.

This finding justifies the efficacy of marital counselling as positively affecting women's attitude towards marital stability. The finding corroborates a similar study in which Onwuasoanya (2006) found that pre-marital guidance has a positive effect on the attitude of undergraduates toward family stability. It further corroborates the views of Owuamanam and Osakinle (2005) that marital stability could be promoted using counselling strategies. They maintained that it enables couples to solve both present and future problems by enabling them learn new methods of interacting positively with one another.

\section{Implications for Counselling}

This study has revealed that marriage counsellors and therapists can utilize marriage counselling techniques in helping women to resolve marital conflicts by changing their attitude positively. It is also useful in enabling women understand their marital roles and responsibilities which will eventually enrich their marital quality and adjustment. This study also implies that counsellors should be versed in marital counselling techniques, especially in the present day where several women are having unresolved marital issues.

\section{Recommendations}

Employers of labour can utilize marriage counselling programmes in bringing about marital stability by organizing symposia, seminars and workshops for women employees in which they can receive pre-marital and post-marital counselling which will develop the women and enable them have a stable marital life that will invariably impact on their input at work. Therefore, marital counselling is advocated for human and personnel resources management.

Young girls should be targeted early in schools using well planned counselling programmes in teaching them desirable attitudes capable of promoting positive changes that will bring about marital stability in future. The government should also mount a sensitization campaign through the news and print media by encouraging women to seek marital counselling which exposes women to ideas and open communication necessary for problem solving. Finally, teaching marital attitudes in institutions of higher learning in Nigeria is recommended as it would help to prepare young girls for marriage by imbibing positive marital 
attitudes which will help in reducing marital instability and the rate of separation and divorce among couples.

\section{Conclusion}

The present study indicated that marital counselling positively impacts on women's attitude towards marital stability. The information derived from this study could be a useful tool for employers of labour and counsellors when used continually. It will help to change women's negative attitude to their marital roles and problem-solving skills.

\section{References}

Adesanya, S. A. (2002). Correlates of marital stability among couples in South Western Nigeria. Unpublished Ph.D Thesis, University of Ado-Ekiti, Nigeria.

Akande, J. A.; Olowonirejuaro, O. A. \& Akuchie, R. C. (2008). Attitude of Colleges of Education Students towards some Essential Concepts for Excellent Academic Performance. Paper presented at the 32nd Annual National Conference of Counselling Association of Nigeria (CASSON) held between $18^{\text {th }}-21^{\text {st }}$ August in University of Ilorin, Nigeria.

Amao-Kehinde, A.O. (2002). The Relative Effectiveness of Conflict Resolution Skills Training on Marital Adjustment of some selected couples. The Counsellor, 19(1), 1-11.

Ambakederemo, E. T. \& Ganagana, T. (2006). Causes of Marital Instability in the Port-Harcourt Municipality, Nigeria: Solutions and Counselling Implications. The Nigerian Journal of Guidance and Counselling, 11(1), 1424.

Campbell, D. P. (1993). The Indirect Assessment of Social Attitudes. Psychological Bulletin, 4715-4738.

Dimkpa, D. I. (2007). Perceived causes of wife Battery by Women in PortHarcourt Urban of Rivers State, Nigeria. Journal of Creativity and Scientific Studies, 2(1), 80-89.

Onwuasoanya, P.N. (2006). Impact of Pre-marital Guidance on Undergraduates' Attitude Toward Family Stability. The Counsellor, 22, 75-81.

Owuamanam, T. O (1997). Marital Satisfaction and Multi-dimensional Factors Among Igbo people in Imo State, Nigeria. Unpublished $\mathrm{PhD}$ Thesis, Ondo State University, Ado-Ekiti, Nigeria.

Owuamanam, T. O \& Osakinle, E. O. (2005). Promoting Family Stability in Ekiti State through Counselling. Paper presented at the Annual National Conference of the Counselling Association of Nigeria (CASSON) held on 16 $6^{\text {th }}-19^{\text {th }}$ August in Calabar, Cross River State of Nigeria. 